\title{
Perfil fermentativo, estabilidade aeróbia e valor nutritivo de silagens de capim-marandu ensilado com aditivos
}

\section{Thiago Fernandes Bernardes ${ }^{1 *}$, Ricardo Andrade Reis ${ }^{2}$, Rafael Camargo do Amaral ${ }^{3}$, Gustavo Rezende Siqueira ${ }^{4}$, Anna Paula de Toledo Piza Roth ${ }^{5}$, Marcella de Toledo Piza Roth ${ }^{5}$, Telma Teresinha Berchielli²}

\author{
${ }^{1}$ Pós-doutoramento - USP/ESALQ. Bolsista FAPESP. \\ 2 Departamento de Zootecnia da FCAVIUNESP. \\ 3 Programa de Pós-graduação em Ciência Animal e Pastagens pela ESALQ/USP. Bolsista FAPESP. \\ ${ }^{4}$ Pólo Regional da Alta Mogiana - Apta - Colina, SP. \\ 5 Programa de Pós-graduação em Zootecnia da FCAVIUNESP. Bolsista FAPESP.
}

RESUMO - Com o objetivo de avaliar as perdas em silagem de capim-marandu produzidas com aditivos foram desenvolvidos dois experimentos. No experimento 1, objetivou-se conhecer o perfil de fermentação e a estabilidade aeróbia de quatro silagens: 1) forragem não tratada (Controle); 2) tratada com Lactobacillus plantarum e Propionibacterium; 3) tratada com Lactobacillus buchneri; e 4) tratada com $0,1 \%$ de benzoato de sódio. No experimento 2, foram utilizados nove novilhos castrados Nelore (PC de $350 \pm 38,9 \mathrm{~kg}$ ), alocados em três quadrados latinos $3 \times 3$ para avaliação do consumo e da digestibilidade das rações contendo $85,4 \%$ das seguintes silagens de capim-marandu: 1) controle; 2) controle com L. plantarum, Pediococcus acidilactici + enzimas fibrolíticas; e 3) tratamento $2+$ L. buchneri. No experimento 1 , as silagens apresentaram baixas recuperações de MS durante a fermentação (média de $86 \%$ ) e os coeficientes de digestibilidade in vitro da matéria seca reduziram de $65,5 \%$ (momento da ensilagem) para 50,0\% no $60^{\circ}$ dia após o fechamento dos silos. No experimento 2, o valor médio de consumo das rações foi de 5,7 kg MS/dia (1,6\% PC) e a digestibilidade de 51,6\% e não diferiram entre as rações. As silagens apresentaram perdas acentuadas na fase fermentativa e o uso de aditivos não alterou essas perdas. A inoculação com bactérias não influenciou o consumo ou a digestibilidade das rações.

Palavras-chave: Brachiaria brizantha, consumo, inoculante, Lactobacillus, perdas

\section{Fermentative profile, aerobic stability, and nutritive value of marandu grass silages using additives at ensiling}

\begin{abstract}
Two trials were conducted to evaluate losses of Marandu grass silages using different additives. The fermentation profile and aerobic stability of the silages were evaluated on the first trial. The followings silages were evaluated: 1 - Marandu grass (Control), 2 - Marandu grass plus L. plantarum and Propionibacterium, 3 - Marandu grass plus L. buchneri, 4 - Marandu grass plus $0.1 \%$ of sodium benzoate. On the second experiment, it was utilized nine castrated Nellore steers (Body weight $350 \pm 38.9 \mathrm{~kg}$ ) allocated in three Latin squares $(3 \times 3)$ to evaluate the intake and digestibility of the total mixed rations containing $85 \%$ of Marandu silage. The followings silages were evaluated: 1 - Marandu grass (Control), 2 - Marandu grass plus L. plantarum, Pediococcus acidilactici associated to fibrolitic enzymes, and 3 - Marandu grass plus L. plantarum, Pediococcus acidilactici associated to fibrolitic enzymes plus $L$. buchneri. On the experiment 1 , the silages showed lowest dry matter recovery (average $86 \%$ ). The in vitro true dry matter digestibility reduced from $65.5 \%$, before Marandu ensilage, to $50.0 \%$ after 60 days of silo closure. On the second trial, the average total mixed feed intake was $5.7 \mathrm{~kg} \mathrm{DM} /$ day $(1.6 \%$ of the BW), and the digestibility values $(51.6 \%)$ was similar among rations. The evaluated silages showed high losses during the fermentative phase, and additive application did not change these profiles. The bacteria application didn't affect the dry matter intake of rations and digestibility values.
\end{abstract}

Key Words: Brachiaria brizantha, inoculant, intake, Lactobacillus, losses

\section{Introdução}

A utilização de inoculantes contendo bactérias homoláticas pode alterar as acentuadas perdas em silagens de capins tropicais, pois essas bactérias competem com os microrganismos existentes na microflora epifítica, aumentando a eficiência fermentativa, em decorrência da maior produção de ácido lático (Kung et al., 2003a), o que poderia

Este artigo foi recebido em 20/11/2006 e aprovado em 17/4/2008.

Correspondências devem ser enviadas para tfbernardes@yahoo.com.

* Endereço atual: Departamento de Zootecnia - Instituto da Saúde e Produção Animal - Universidade Federal Rural da Amazônia, Belém - PA. 
levar a maior consumo e desempenho dos animais (McDonald et al., 1991).

Entretanto, silagens resultantes de fermentação desejável, em virtude da elevada concentração de lactato, geralmente são mais propensas à deterioração aeróbia (Weinberg et al., 1993). Assim, o uso de bactérias heteroláticas, como Lactobacillus buchneri, tem proporcionado resultados promissores no aumento da estabilidade aeróbia em silagens e ganhos no desempenho de bovinos leiteiros (Kung et al., 2003b). Segundo Driehuis et al. (2001), a aplicação conjunta de bactérias homofermentativas e L. buchneri na ensilagem pode acelerar a fermentação lática inicial e reduzir a susceptibilidade de deterioração pelos microrganismos aeróbios.

Nishino et al. (2003) ressaltaram que a fermentação pela bactéria $L$. buchneri produz, além do ácido acético, o 1,2 propanodiol, que, quando ingerido, pode ser transformado em ácido propiônico pelas bactérias ruminais, o que melhoraria o desempenho de animais ruminantes.

As bactérias do gênero Propionobacterium também têm sido estudadas visando ao controle da estabilidade aeróbia em silagens, pois produzem propionato, um composto anti-fúngico. Contudo, Kung et al. (2003a) autores relataram que os aumentos na estabilidade aeróbia encontrados na literatura são questionáveis, pois essas bactérias não proliferam com eficácia em pH inferior a 4,0. FloresGalarza et al. (1985), no entanto, estudaram a associação de L. plantarum e $P$. shermanii e notaram redução na população de leveduras em silagem de grãos úmidos de milho.

Com a proposta de diminuir o número de microrganismos indesejáveis, agentes conservantes utilizados na indústria alimentícia têm sido testados para o controle de qualidade de alimentos para os animais, como é o caso do benzoato de sódio (Bernardes et al., 2007). Segundo Kung et al. (2003a), o ácido benzóico pode ter efeito estabilizante na massa e controlar microrganismos indesejáveis, como os fungos.

Neste trabalho, avaliaram-se o perfil de fermentação e a estabilidade aeróbia de silagens de capim-marandu tratadas com benzoato de sódio e inoculantes bacterianos e determinaram-se o consumo e a digestibilidade de rações contendo estas silagens inoculadas com bactérias homofermentativas associadas a Lactobacillus buchneri.

\section{Material e Métodos}

O experimento foi conduzido nas dependências da Faculdade de Ciências Agrárias e Veterinárias - UNESP, localizada em Jaboticabal, São Paulo ( $21^{\circ} 15^{\prime}$ S e $\left.48^{\circ} 18^{\prime} \mathrm{W}\right)$.
O capim-marandu (Brachiaria brizantha (Hochst ex. A. Rich) Stapf cv. Marandu) foi colhido no dia 12 de dezembro de 2003, aos 50 dias de crescimento vegetativo (Tabela 1), utilizando-se máquina forrageira marca Casale modelo CFC 2000.

A forragem colhida foi submetida aos tratamentos com Lactobacillus plantarum cepa MA 18/5U + Propionibacterium cepa MS01; Lactobacillus buchneri cepa NCIMB 40788; ou 0,1\% de benzoato de sódio (Tabela 2).

Os aditivos foram aplicados à forragem minutos antes do enchimento dos silos, na forma de solução aquosa (água destilada), por meio de pulverizador manual, buscando-se distribuição uniforme na massa de forragem. O inoculante Propiolact (Lallemand) foi utilizado como fonte das bactérias L. plantarum e Propionibacterium (concentração de 1,5 $\times$ $10^{5}$ bactérias/g de forragem). Na aplicação de L. buchneri ( $5 \times 10^{4}$ bactérias/g de forragem), foi utilizado o Lalsil Cana (Lallemand).

Como silos experimentais, foram utilizados 48 baldes plásticos com capacidade de 7,5 L, compondo três repetições por tempo de abertura. No fundo dos baldes, foram colocados $1,5 \mathrm{~kg}$ de areia e duas telas finas de plástico (tipo sombrite), que funcionaram como dreno para o efluente. A compactação foi realizada por meio de bastões de ferro, com acomodação de camadas de aproximadamente $5-10 \mathrm{~cm}$ de espessura atingindo densidade média de $590 \mathrm{~kg}$ de matéria verde $/ \mathrm{m}^{3}$.

Cada balde, após a ensilagem, recebeu tampa de plástico apropriada à vedação e adaptada com válvula do tipo Bunsen para escape dos gases. Em seguida, os baldes foram pesados e armazenados em temperatura ambiente.

A avaliação do perfil de fermentação foi realizada nos tempos 1, 5, 15 e 60 dias após o fechamento dos silos. Nos respectivos dias de abertura, os silos foram pesados para avaliação da perda de gás e, após a retirada da silagem, o conjunto balde + areia foi pesado novamente para determinação da produção de efluente. Como análises químicas das silagens, foram determinadas as concentrações de matéria seca (MS), proteína bruta (PB) e nitrogênio amoniacal em relação ao nitrogênio total $\left(\mathrm{N}-\mathrm{NH}_{3}\right)$ e da digestibilidade

Tabela 1 - Características da forrageira no momento da ensilagem

\begin{tabular}{ll} 
Variável & \\
\hline Altura $(\mathrm{cm})$ & 105 \\
Massa de forragem (t MS/ha) & 7,1 \\
Folha $(\%)^{*}$ & 54 \\
Caule $(\%)^{*}$ & 46 \\
\hline
\end{tabular}

*Colheita acima de $15 \mathrm{~cm}$ do solo. 
Tabela 2 - Composição química da forragem antes da ensilagem

\begin{tabular}{|c|c|c|c|c|c|c|}
\hline \multirow[t]{2}{*}{ Variável } & \multicolumn{4}{|c|}{ Tratamento } & \multirow[t]{2}{*}{ Média } & \multirow[t]{2}{*}{$\mathrm{EPM}^{1}$} \\
\hline & $\begin{array}{c}\text { Controle } \\
\text { (sem aditivo) }\end{array}$ & $\begin{array}{c}\text { Lactobacillus plantarum }+ \\
\text { Propionibacterium }\end{array}$ & $\begin{array}{l}\text { Lactobacillus } \\
\text { buchneri }\end{array}$ & $\begin{array}{l}\text { Benzoato } \\
\text { de sódio }\end{array}$ & & \\
\hline Matéria seca (\%) & 17,1 & 16,9 & 17,0 & 16,8 & 16,9 & 0,13 \\
\hline Cinzas (\% MS) & 8,6 & 8,5 & 8,6 & 8,5 & 8,5 & 0,10 \\
\hline Proteína bruta (\% MS) & 6,8 & 6,7 & 5,8 & 6,3 & 6,4 & 0,20 \\
\hline FDN (\% MS) & 73,3 & 73,4 & 73,5 & 73,7 & 73,6 & 0,33 \\
\hline FDA (\% MS) & 50,5 & 52,0 & 52,9 & 51,5 & 51,7 & 0,54 \\
\hline Celulose (\% MS) & 43,9 & 45,4 & 46,2 & 45 & 45,1 & 0,54 \\
\hline Hemicelulose (\% MS) & 22,8 & 21,9 & 20,6 & 22,2 & 21,9 & 0,44 \\
\hline Lignina (\% MS) & 6,6 & 6,6 & 6,7 & 6,5 & 6,6 & 0,21 \\
\hline DIVMS $(\%)^{2}$ & $66,8 \mathrm{a}$ & $64,5 \mathrm{bc}$ & $63,9 \mathrm{c}$ & $66,7 \mathrm{ab}$ & 65,5 & 0,44 \\
\hline $\mathrm{pH}$ & 5,8 & 5,9 & 5,9 & 5,8 & 5,9 & 0,35 \\
\hline
\end{tabular}

${ }^{1}$ EPM $=$ erro-padrão da média ${ }^{2}$ DIVMS = digestibilidade verdadeira in vitro da matéria seca.

Letras distintas nas linhas indicam valores diferentes $(P<0,05)$.

in vitro da matéria seca (DIVMS), conforme descrito por Silva \& Queiroz (2002). As concentrações de fibra em detergente neutro (FDN) e fibra em detergente ácido (FDA) foram avaliadas pelo método seqüencial, segundo técnicas descritas por Robertson \& Van Soest (1981), e os valores de $\mathrm{pH}$, conforme relatado por Kung et al. (1984).

A estabilidade aeróbia foi avaliada 60 dias após a vedação dos silos, quando os baldes foram abertos e todo o seu conteúdo foi transferido para bandejas de plástico para posterior homogeneização. Em seguida, $1,5 \mathrm{~kg}$ de silagem foi colocado em caixas de isopor, transferidas para câmara climática a $25 \pm 1^{\circ} \mathrm{C}$. As temperaturas das silagens foram medidas duas vezes ao dia, durante seis dias, com o uso de termômetro inserido a $10 \mathrm{~cm}$, no centro da massa. A temperatura do ambiente foi controlada pelo termostato do aparelho refrigerador e também por meio de termômetros suspensos no ar. A estabilidade aeróbia foi calculada como o tempo para que a temperatura da silagem aumentasse $2^{\circ} \mathrm{C}$ em relação à temperatura ambiente após a abertura do silo (Moran et al., 1996). Também como medida física, foi avaliada a recuperação de $\mathrm{MS}$ em aerobiose ao final de seis dias de exposição ao ambiente.

Em outro conjunto de caixas de isopor, foi colocada a mesma quantidade de silagem $(1,5 \mathrm{~kg})$, que foi levada à câmara climática com o objetivo de determinar as alterações de pH, colhendo-se amostras com 0, 3 e 6 dias de aeração.

O delineamento experimental utilizado na avaliação do perfil de fermentação e da estabilidade aeróbia foi o inteiramente casualizado, com três repetições, em esquema de parcelas subdivididas, no qual os tratamentos foram as parcelas e os tempos, as subparcelas, de acordo com o modelo:

$$
\mathrm{Y}_{\mathrm{ijk}}=\mu+\mathrm{S}_{\mathrm{i}}+\varepsilon_{(\mathrm{a})}+\mathrm{T}_{\mathrm{j}}+\mathrm{ST}_{\mathrm{ij}}+\varepsilon_{(\mathrm{b})}
$$

em que: $\mu=$ média geral; $S_{i}=$ efeito de silagem $(i=1$ a 4$)$;
$\mathrm{T}_{\mathrm{j}}=$ efeito de tempo $(\mathrm{j}=1 \mathrm{a} 4) ; \mathrm{ST}_{\mathrm{ij}}=$ interação silagem $\times$ tempo; $\varepsilon=$ erro residual.

Os dados experimentais foram submetidos à análise de variância e as médias foram comparadas pelo teste de Tukey, a 5\% de probabilidade, utilizando-se o PROC MIXED do programa SAS (1999).

O experimento para análise do consumo e da digestibilidade foi conduzido em Jaboticabal, São Paulo, a $21^{\circ} 15^{\prime} \mathrm{S}$ e $48^{\circ} 18^{\prime} \mathrm{W}$. No dia 26 de março de 2004 , procedeu-se à colheita do capim-marandu $(15 \mathrm{~cm}$ de altura do solo), aos 58 dias de crescimento vegetativo (Tabela 3 ), utilizando-se máquina forrageira Casale, modelo CFC 2000. Foram confeccionados três silos do tipo superfície com capacidade média de 13 toneladas: forragem não tratada (controle); forragem tratada com L. plantarum cepa MA 18/5U, Pediococcus acidilactici cepa MA 18/5M + celulase e hemicelulase (LPPA); e forragem tratada com LPPA $+L$. buchneri cepa NCIMB 40788 (LPPA + LB).

Soluções aquosas contendo os inoculantes foram pulverizadas sobre a forragem, no momento da ensilagem, por meio de pulverizador costal. No momento da aplicação, a concentração de bactérias nos tratamentos LPPA e LPPA + LB foram de: L. plantarum $1 \times 10^{5} / \mathrm{g}$ forragem, $P$. acidilactici $3 \times 10^{4} / \mathrm{g}$ e L. buchneri $5 \times 10^{4} / \mathrm{g}$. As enzimas

Tabela 3 - Características da forrageira no momento da ensilagem

Variável

Altura $(\mathrm{cm})$

Massa de forragem (t MS/ha)

Matéria seca $(\%)$ 115

Proteína bruta $(\%)$

Fibra em detergente neutro (\%)

32,3

5,8

*Colheita acima de $15 \mathrm{~cm}$ do solo. 
celulase e hemicelulase (1\%) e as bactérias L. plantarum e $P$. acidilactici são encontradas no inoculante comercial Lalsil PS (Lallemand) e a bactéria L. buchneri, no produto Lalsil Cana (Lallemand). A dosagem dos inoculantes foi realizada de acordo com a quantidade de forragem contida em cada vagão forrageiro utilizado no transporte.

$\mathrm{O}$ experimento foi conduzido em três períodos de 17 dias, totalizando 51 dias, com início no dia 6/6 e final 27/7/2004. Utilizaram-se nove novilhos da raça Nelore, castrados, com $350 \pm 38,9 \mathrm{~kg}$ de peso corporal, alocados em três quadrados latinos $3 \times 3$. Durante o período de adaptação (cinco dias) e coleta de dados de consumo (seis dias), os animais foram mantidos em baias individuais, cobertas e providas de piso de concreto, bebedouros e cochos para fornecimento da ração. O período de coleta dos dados de digestibilidade (sete dias) foi realizado em gaiolas para estudos de metabolismo, mantidas em galpão coberto e providas de comedouro, bebedouro e bandejas para coleta total de fezes. Antes do início do experimento, os novilhos foram tratados contra carrapatos e everminados.

Como tratamentos, foram avaliadas três rações, que diferiram quanto ao tipo de silagem de capim-marandu utilizada nas suas composições (Tabela 4). Os ingredientes tiveram a seguinte participação $(\% \mathrm{MS})$ : silagem de capim = $84,52 \%$; milho grão moído $=13,56 \%$; uréia $=1,56 \%$; premix mineral vitamínico $=0,37 \%$. As dietas foram calculadas utilizando-se as equações do programa NRC - Gado de corte (1996) objetivando maior uso de volumoso, com ganho médio diário de $0,2 \mathrm{~kg}$ para novilhos Nelore em crescimento e pesando $350 \mathrm{~kg}$.

A quantidade de ração fornecida aos animais durante o período de coleta foi ajustada para que houvesse $10 \%$ de sobras. Os animais foram alimentados uma vez ao dia $(8 \mathrm{~h})$ e a água foi fornecida à vontade. Durante o período de coleta, as rações fornecidas e as sobras foram amostradas diariamente e acondicionadas em sacos plásticos formando amostra composta. As fezes foram coletadas diariamente pela manhã e, em seguida, foram pesadas, homogeneizadas e conservadas em freezer.

Ao término de cada período de coleta, as amostras compostas de fezes e de alimentos foram secas em estufa de ventilação forçada a $55^{\circ} \mathrm{C}$ por 72 horas e, posteriormente, foram moídas até as partículas atingirem menos de $1 \mathrm{~mm}$ e armazenadas em recipientes plásticos. Nas amostras secas e moídas, foram determinadas as concentrações de matéria seca e cinzas, conforme descrito por Silva \& Queiroz (2002), e de FDN, segundo técnicas descritas por Robertson \& Van Soest (1981).

Durante o período em que os animais foram alimentados, o painel de cada silo foi avaliado com o objetivo de se estimar o grau de deterioração das silagens após a quebra da vedação. A partir do sétimo dia de aeração (quando o fenômeno foi detectado), antes de se iniciar o manejo, a silagem que apresentava problemas visuais (aspecto deteriorado) e temperatura excessiva em relação ao restante do painel foi recolhida, pesada e descartada, o que permitiu avaliar as perdas do total removido diariamente dos silos.

Durante o desabastecimento dos silos, foram avaliadas as densidades, retirando-se massa de silagem com volume conhecido por meio de cortes no painel com auxílio de motosserra até o valor médio de $450 \mathrm{~kg}$ de matéria verde $/ \mathrm{m}^{3}$.

O delineamento utilizado foi o quadrado latino $3 \times 3$, com três animais, três períodos e três quadrados, de acordo com o modelo:

$$
\mathrm{Y}_{\mathrm{ijkl}}=\mu+\mathrm{Q}_{\mathrm{i}}+\mathrm{A}(\mathrm{Q})_{\mathrm{j}(\mathrm{i})}+\mathrm{P}(\mathrm{Q})_{\mathrm{k}(\mathrm{i})}+\mathrm{R}_{1}+\varepsilon_{\mathrm{ijkl}}
$$

em que: $\mu=$ média geral; $Q_{i}=$ efeito de quadrado $(i=1$ a 3$)$; $\mathrm{A}(\mathrm{Q})_{\mathrm{j}(\mathrm{i})}=$ efeito de animal dentro de quadrado $(\mathrm{j}=1$ a 9$)$; $\mathrm{P}(\mathrm{Q})_{\mathrm{k}(\mathrm{i})}=$ efeito de período dentro de quadrado $(\mathrm{k}=1$ a 3$)$; $\mathrm{S}_{1}=$ efeito de rações $(1=1$ a 3$)$; e $\varepsilon_{i j k l}=$ erro residual.

Os dados experimentais foram submetidos à análise de variância e as médias foram comparadas pelo teste de Tukey, a 5\% de probabilidade, utilizando-se o PROC GLM do programa SAS (1999).

Tabela 4 - Composição química das silagens e das rações (experimento 2)

\begin{tabular}{|c|c|c|c|c|c|c|}
\hline \multirow[t]{2}{*}{ Variável } & \multicolumn{3}{|c|}{ Silagem $^{1}$} & \multicolumn{3}{|c|}{ Ração ${ }^{2}$} \\
\hline & Controle & LPPA & $\mathrm{LPPA}+\mathrm{LB}$ & Controle & LPPA & $\mathrm{LPPA}+\mathrm{LB}$ \\
\hline Matéria seca $(\%)$ & 29,8 & 32,1 & 29,7 & 34,1 & 35,2 & 34,8 \\
\hline Matéria orgânica (\% MS) & 87,6 & 89,9 & 90,1 & 92,3 & 93,1 & 92,9 \\
\hline Cinzas (\% MS) & 8,8 & 7,3 & 7,1 & 6,6 & 7,1 & 6,5 \\
\hline Proteína bruta (\% MS) & 5,8 & 4,9 & 5,6 & 9,7 & 10,1 & 10,5 \\
\hline FDN (\% MS) & 79,5 & 79,3 & 78,8 & 74,3 & 74,9 & 75,1 \\
\hline FDA ( \% MS) & 46,8 & 47,2 & 47,3 & 45,8 & 44,3 & 44,9 \\
\hline $\mathrm{pH}$ & 4,6 & 4,5 & 4,4 & - & - & - \\
\hline $\mathrm{N}-\mathrm{NH}_{3}(\% \quad \mathrm{~N}$ total $)$ & 4,6 & 3,6 & 3,2 & - & - & - \\
\hline
\end{tabular}

${ }^{1}$ Média de três amostras coletadas no início, meio e fim de cada silo; LPPA = L. plantarum, Pediococcus acidilactici + celulase e hemicelulase; $\mathrm{LPPA}+\mathrm{LB}=\mathrm{LPPA}+$ L. buchneri. 


\section{Resultados e Discussão}

As silagens não apresentaram, durante o processo fermentativo, alteração na concentrações de matéria secas (Tabela 5), cujo valor médio foi de 18,0\%. As concentrações de FDN e FDA apresentaram ligeira redução até o $50^{\circ}$ dia de fermentação em todas as silagens estudadas, possivelmente em virtude do efeito da hidrólise ácida e enzimática da hemicelulose, pois, durante a fase inicial de ensilagem, enzimas das células vegetais e dos microrganismos envolvidos na fermentação rompem a estrutura celular, quebrando as ligações químicas dos carboidratos estruturais, principalmente da hemicelulose (Winters et al., 1987). Do 50으 ao 60 을a, houve elevação das concentrações de FDN e FDA, o que pode ser explicado pela redução de conteúdo celular, que ocasiona elevação proporcional dos constituintes da parede celular, uma vez que essas análises são determinadas por método gravimétrico.

No $60^{\circ}$ dia, as concentrações de $\mathrm{PB}$ diminuíram $(\mathrm{P}<0,05)$ em relação aos dias antecedentes, enquanto as concentrações de $\mathrm{N}-\mathrm{NH}_{3}$ (Tabela 5) tiveram comportamento inverso. Possivelmente, houve atuação de microrganismos como enterobactérias e/ou Clostridium, o que provocou fermentações indesejáveis nas silagens. Os valores de $\mathrm{N}_{-} \mathrm{NH}_{3}$ são considerados aceitáveis na silagem com benzoato de sódio, que apresentou a menor concentração $(5,1 \%) 60$ dias após a vedação dos silos. Bernardes et al. (2005) constataram instabilidade da população de clostrídeos em silagens de capim-marandu durante a fermentação e elevação do número destas bactérias após o 28으 dia de ensilagem. Os clostrídeos podem ser inibidos durante os primeiros dias de ensilagem com a redução do $\mathrm{pH}$. Entretanto, podem retomar o crescimento com o tamponamento do meio ao longo da fermentação pelos compostos produzidos.

Os valores de $\mathrm{pH}$ nas silagens estudadas (Tabela 5) após um dia de fermentação reduziram de 5,9 para 4,7 e mantiveram-se estáveis até o $50^{\circ}$ dia (média $=4,6$ ), com elevação $(\mathrm{P}<0,05)$ no 60 o dia (média $=5,1)$, o que poderia comprovar a presença de bactérias do gênero Clostridium, levando ao consumo de ácido lático, pois, segundo Pahlow et al. (2003), as espécies sacarolíticas (Clostridium tyrobotyricum) assimilam este ácido como fonte de energia. Segundo Driehuis et al. (2001), o L. buchneri durante a fermentação pode consumir lactato, transformando-o em acetato, o que pode ter elevado o $\mathrm{pH}$ na silagem com $L$. Buchneri.

A expectativa que a silagem LPPB apresentasse $\mathrm{pH}$ inferior ao das demais silagens com a presença da bactéria L. plantarum não foi comprovada. É possível que as características inerentes à forragem (concentração de MS e de carboidratos solúveis) não tenham sido favoráveis ao desenvolvimento destas bactérias. Coan et al. (2005) estudaram o efeito da inoculação L. plantarum, Enterococcus faecium e Pediococcus $\left(1,5 \times 10^{5}\right.$ bactérias/g forragem) em silagens de capim-tanzânia e capim-mombaça em duas idades de corte ( 45 e 60 dias) e verificaram que a presença do inóculo não alterou os valores de $\mathrm{pH}$ e as concentrações de ácido lático e $\mathrm{N}-\mathrm{NH}_{3}$ nas silagens avaliadas.

As perdas por gases ao longo do processo fermentativo até o 50 - dia aumentaram $(\mathrm{P}<0,05)$ e foram semelhantes nas silagens avaliadas (Tabela 5). Aumento significativo na produção de gás foi observado aos 60 dias após a ensilagem $(\mathrm{P}<0,05)$, com valor máximo correspondente ao da silagem com L. buchneri. A produção de $\mathrm{CO}_{2}$, em virtude da rota heterolática de fermentação pelo L. buchneri, pode explicar esses resultados. As maiores perdas nas demais silagens no $60^{\circ}$ dia podem ser atribuídas à presença de fermentações secundárias, uma vez que houve aumento dos valores de $\mathrm{pH}$ e $\mathrm{N}-\mathrm{NH}_{3}$.

A produção de efluente foi maior na silagem controle, cuja média final foi de $68,5 \mathrm{~kg} / \mathrm{t} \mathrm{MV}$, seguida pela silagem L. buchneri, cujo valor médio foi de 59,5 kg/t MV (Tabela 5). Mari (2003) encontrou valor de 39,6 kg/t MV em silagens de capim-marandu com 19,5\% MS, no entanto, a comparação de resultados para este tipo de variável se torna difícil, pois, além das concentrações de MS da planta, a pressão de compactação no momento da ensilagem e o grau de picagem da forragem são fatores relevantes. Neste estudo, as silagens apresentaram densidade média de $590 \mathrm{~kg}$ de $\mathrm{MV} / \mathrm{m}^{3}$.

A silagem com benzoato de sódio atingiu a maior recuperação de matéria seca $(\mathrm{P}<0,05) 60$ dias após o fechamento dos silos (Tabela 5). Os menores valores de $\mathrm{pH}$, $\mathrm{N}-\mathrm{NH}_{3}$ e gás também foram observados nesta silagem, o que repercutiu favoravelmente para essa variável. As silagens controle e L. buchneri apresentaram as menores recuperações de MS, em decorrência das maiores perdas de gases e efluente.

Os valores de DIVMS (Tabela 5) diminuíram de nove pontos percentuais ao longo do processo fermentativo $(58,7$ e $50,0 \%, 10$ e $60 \underline{0}$ dias, respectivamente), principalmente do $50^{\circ}$ para o $60^{\circ}$ dia $(\mathrm{P}<0,05)$. Os valores de DIVMS no momento da ensilagem (Tabela 2) e após 24 horas de fermentação são relevantes, uma vez que ocorreu redução de $65,5 \%$ para $58,7 \%$ (sete pontos percentuais). Contudo, a recuperação de MS nas silagens após um dia de fermentação foi baixa e pode ser explicada pela elevada produção de efluente nas silagens (26,3 g/kg MV - média do primeiro dia de ensilagem), pois o efluente é constituído principalmente de conteúdo celular. Do total de efluente, 31,5\% 
foram produzidos após 24 horas de fermentação, situação semelhante à observada por Loures et al. (2003), que verificaram que $55 \%$ da produção de efluente durante a ensilagem ocorreu nos dois primeiros dias após o fechamento dos silos.

As concentrações de MS, valor médio de 20,8\%, aumentaram durante a exposição ao $\operatorname{ar}(\mathrm{P}<0,05)$, em virtude da evaporação de água na massa de silagem para o ambiente (Tabela 6).

Os valores de $\mathrm{pH}$ aumentaram do primeiro para o terceiro dia de exposição aeróbia $(\mathrm{P}<0,05)$ e se mantiveram estáveis após seis dias de aeração. Entre as silagens, aquelas inoculadas com L. plantarum apresentaram as maiores altas $(\mathrm{P}<0,05)$. Após a quebra da vedação, os microrganismos aeróbios iniciam seu crescimento e podem utilizar o ácido lático como fonte de energia, o que determina o aumento dos valores de $\mathrm{pH}$ quando as silagens são expostas ao ar
(Weinberg et al., 1993). Os valores de DIVMS mantiveram-se estáveis por todo o período de aeração, com valores semelhantes aos das silagens quando os silos foram abertos.

As temperaturas das silagens em estudo podem ser consideradas estáveis, considerando a metodologia adotada (Figura 1), e não ultrapassaram $2^{\circ} \mathrm{C}$ a temperatura ambiente $\left(25^{\circ} \mathrm{C}\right)$ durante os seis dias de aeração. Bernardes et al. (2003) relataram que silagens de gramíneas tropicais com menos de $30 \%$ de MS são mais propensas à deterioração por bactérias (Bacillus e Enterobactérias), em virtude da estabilidade de fermentação em $\mathrm{pH}$ acima de 4,5 , concentração de umidade e ausência de substrato para as leveduras, que são sensíveis a fonte de nutrientes. O inverso ocorre com silagens de alta qualidade, como as de milho e de sorgo, que são deterioradas principalmente por fungos filamentosos e leveduras (Muck, 2004), o que provoca elevação de temperatura (McDonald et al., 1991). Segundo

Tabela 5 - Características de silagens de capim-marandu tratado com aditivos bacterianos e químico na fermentação (experimento 1)

\begin{tabular}{|c|c|c|c|c|c|c|c|c|c|c|c|c|}
\hline \multirow[t]{2}{*}{ Variável } & \multicolumn{4}{|c|}{$\begin{array}{c}\text { Tratamento } \\
\text { (A) })^{1}\end{array}$} & \multicolumn{4}{|c|}{$\begin{array}{l}\text { Dias após o } \\
\text { fechamento (B) }\end{array}$} & \multicolumn{3}{|c|}{$\begin{array}{c}\text { Efeitos e } \\
\text { interações }(\mathrm{P}<)^{2}\end{array}$} & \multirow[t]{2}{*}{$\mathrm{EPM}^{3}$} \\
\hline & Controle & LPPB & LB & BS & 1 & 5 & 15 & 60 & A & B & $\mathrm{A} \times \mathrm{B}$ & \\
\hline Matéria seca $(\%)$ & $17,8 \mathrm{~b}$ & $18,2 \mathrm{a}$ & $18,0 \mathrm{a}$ & $18,3 \mathrm{a}$ & 17,8 & 18,0 & 18,1 & 18,0 & * & NS & NS & 0,10 \\
\hline FDN (\% MS) & 72,0 & 72,5 & 73,1 & 71,9 & $72,7 b$ & $71,4 \mathrm{c}$ & $71,0 \mathrm{c}$ & $74,2 \mathrm{a}$ & NS & $* *$ & $* *$ & 0,37 \\
\hline FDA (\% MS) & 47,0 & 46,5 & 49,1 & 46,7 & $48,1 \mathrm{a}$ & $46,1 b$ & $44,7 \mathrm{c}$ & $50,5 \mathrm{a}$ & NS & $* *$ & NS & 0,90 \\
\hline Proteína bruta (\% MS) & $5,7 \mathrm{~b}$ & $6,2 \mathrm{a}$ & $6,2 \mathrm{a}$ & $6,2 \mathrm{a}$ & $6,6 a$ & $6,4 \mathrm{a}$ & $6,3 \mathrm{a}$ & $5,0 \mathrm{~b}$ & $* *$ & $* *$ & * & 0,09 \\
\hline $\mathrm{N}-\mathrm{NH}_{3}(\% \mathrm{~N}$ total $)$ & $3,6 \mathrm{a}$ & $3,6 \mathrm{a}$ & $3,2 \mathrm{ab}$ & $2,4 b$ & $1,4 \mathrm{c}$ & $1,8 \mathrm{bc}$ & $2,3 b$ & $7,3 \mathrm{a}$ & $* *$ & $* *$ & $*$ & 0,24 \\
\hline $\mathrm{pH}$ & 4,7 & 4,7 & 4,8 & 4,7 & $4,7 \mathrm{~b}$ & $4,6 \mathrm{~b}$ & $4,6 b$ & $5,1 \mathrm{a}$ & NS & $* *$ & $* *$ & 0,02 \\
\hline Gases (\% MS) & 2,9 & 2,9 & 3,6 & 2,5 & $0,7 \mathrm{c}$ & $1,6 \mathrm{bc}$ & $2,7 \mathrm{~b}$ & $7,0 \mathrm{a}$ & NS & $* *$ & $* *$ & 0,32 \\
\hline Efluente (kg/t MV) & $68,5 \mathrm{a}$ & $48,2 \mathrm{c}$ & $59,5 \mathrm{~b}$ & $56,6 \mathrm{~b}$ & $26,3 \mathrm{c}$ & $47,5 b$ & $76,6 \mathrm{a}$ & $82,5 \mathrm{a}$ & $* *$ & ** & NS & 2,61 \\
\hline $\operatorname{RMS}(\%)^{4}$ & $89,1 \mathrm{c}$ & $92,0 \mathrm{~b}$ & $90,9 b$ & $92,5 \mathrm{a}$ & $92,9 \mathrm{a}$ & $93,0 \mathrm{a}$ & $93,0 \mathrm{a}$ & $86,4 \mathrm{~b}$ & $* *$ & $* *$ & NS & 0,53 \\
\hline DIVMS $(\%)^{5}$ & 56,5 & 56,6 & 56,0 & 56,1 & $58,7 \mathrm{a}$ & $60,0 \mathrm{a}$ & $56,3 b$ & $50,1 \mathrm{c}$ & NS & $* *$ & NS & 0,57 \\
\hline
\end{tabular}

1 LPPB = L. plantarum e Propionibacterium, LB = L. buchneri, BS = benzoato de sódio.

2 ns = não significativo, ${ }^{*}(\mathrm{P}<0,05),{ }^{* *}(\mathrm{P}<0,01)$.

${ }^{3} \mathrm{EPM}=$ erro-padrão da média.

${ }^{4}$ RMS = recuperação de matéria seca.

5 DIVMS = digestibilidade in vitro da matéria seca.

Letras distintas nas linhas indicam valores estatisticamente diferentes.

Tabela 6 - Características de silagens de capim-marandu tratado com aditivos bacterianos e químico durante a exposição ao ar (experimento 1)

\begin{tabular}{|c|c|c|c|c|c|c|c|c|c|c|c|}
\hline \multirow[t]{2}{*}{ Variável } & \multicolumn{4}{|c|}{$\begin{array}{l}\text { Tratamento } \\
\text { (A) }{ }^{1}\end{array}$} & \multicolumn{3}{|c|}{$\begin{array}{c}\text { Dias de } \\
\text { exposição (B) }\end{array}$} & \multicolumn{3}{|c|}{$\begin{array}{c}\text { Efeitos e } \\
\text { interações }(\mathrm{P}<)^{2}\end{array}$} & \multirow[t]{2}{*}{$\mathrm{EPM}^{3}$} \\
\hline & Controle & LPPB & LB & BS & 0 & 3 & 6 & A & $\mathrm{B}$ & $\mathrm{A} \times \mathrm{B}$ & \\
\hline Matéria seca $(\%)$ & 21,1 & 20,4 & 20,9 & 20,8 & $17,7 \mathrm{a}$ & $23,5 b$ & $21,1 b$ & NS & $* *$ & NS & 1,28 \\
\hline $\mathrm{pH}$ & $5,2 b$ & $5,4 \mathrm{a}$ & $5,1 b$ & $5,1 b$ & $5,1 \mathrm{c}$ & $5,3 \mathrm{a}$ & $5,2 b$ & $*$ & $* *$ & $*$ & 0,09 \\
\hline DIVMS $(\%)^{4}$ & 49,1 & 49,7 & 51,8 & 51,4 & 50,9 & 50,0 & 50,1 & NS & NS & NS & 2,07 \\
\hline Recuperação de MS $(\%)^{5}$ & 99,9 & 98,1 & 98,6 & 98,5 & - & - & - & NS & - & - & 0,86 \\
\hline
\end{tabular}

${ }^{1} \mathrm{LPPB}=$ L. plantarum e Propionibacterium, LB $=$ L. buchneri, BS = benzoato de sódio.

2 ns = não-significativo, ${ }^{*}(\mathrm{P}<0,05),{ }^{* *}(\mathrm{P}<0,01)$.

3 EPM = erro-padrão da média.

4 DIVMS = digestibilidade verdadeira in vitro da matéria seca,

${ }^{5} \mathrm{RMS}$ = recuperação de matéria seca - seis dias de exposição ao ambiente.

Letras distintas nas linhas indicam valores estatisticamente diferentes. 


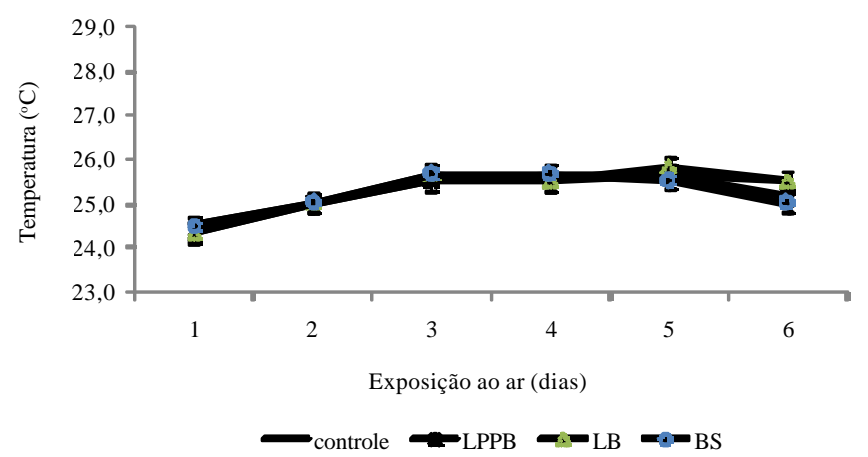

Figura 1 - Variação temporal da temperatura das silagens de capim-marandu tratado com aditivos bacterianos e químico durante a exposição ao ar (experimento 1).

LPPB $=$ L. plantarum e Propionibacterium, $\mathrm{LB}=$ L. buchneri, $\mathrm{BS}=$ Benzoato de sódio. A estabilidade aeróbia foi definida como o tempo observado para que a silagem apresentasse elevação de $2^{\circ} \mathrm{C}\left(27^{\circ} \mathrm{C}\right)$ em relação à temperatura ambiente $\left(25^{\circ} \mathrm{C}\right)$.

Östling \& Lindgren (1995), a presença de enterobactérias torna as silagens mais estáveis durante a aerobiose, em virtude da produção de alguns compostos durante a fermentação, que inibem as leveduras durante a exposição ao $\mathrm{O}_{2}$.

As silagens de capim-marandu, com concentrações de MS próximas a $20 \%$, são estáveis em condições de aerobiose, mesmo na presença de inoculante contendo bactéria produtora de ácido lático (L. plantarum). Os incrementos com outros ácidos, provenientes da fermentação por L. buchneri (ácido acético) e pela adição de benzoato de sódio (ácido benzóico), utilizados nos tratamentos LB e BS, com vistas a reduzir a susceptibilidade destas silagens à deterioração aeróbia, não se fazem necessários, devido às particularidades (estabilidade de fermentação em pH acima de 4,5, concentração de umidade e ausência de substrato) apresentadas por esta espécie forrageira, reduzindo a atividade de fungos e leveduras durante a aeração, corroborando os resultados obtidos por Bernardes et al. (2007).

Andrade \& Melotti (2003) avaliaram as características fermentativas de silagem de capim-elefante com $15 \%$ de MS e encontraram concentração de ácido acético de 3,2\%. Essa concentração de acetato é elevada, pois é característica de silagem de milho inoculada com L. buchneri na concen tração de $1 \times 10^{6}$ bactérias/g de forragem, como por Ranjit \& Kung (2000). Camargo et al. (2004) estudaram a estabilidade aeróbia de silagem de capim-marandu com diversas concentrações de umidade e relataram que a silagem com 20,4\% de MS foi mais estável que aquela com $35 \%$ de MS e a quebra da estabilidade ocorreu aos 13 e 6 dias de aeração.

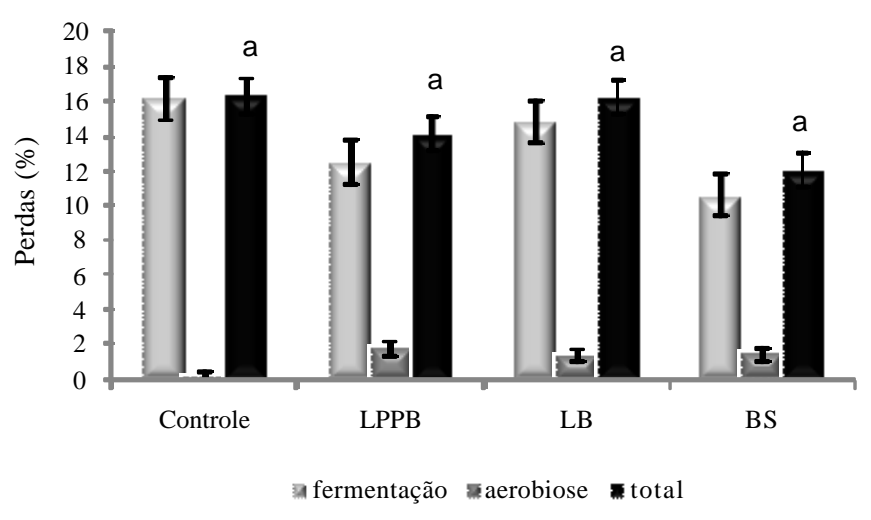

Figura 2 - Perdas de matéria seca das silagens de capimmarandu tratado com aditivos bacterianos e químico, após 60 dias de fermentação e seis dias de exposição aeróbia (experimento1).

$\mathrm{LPPB}=$ L. plantarum e Propionibacterium, LB $=$ L. buchneri, $\mathrm{BS}=$ Benzoato de sódio, $\mathrm{RMS}$ total $=\left[\left(\mathrm{RMS}_{\text {fermentação }} \mathrm{X}\right.\right.$ $\left.\left.\mathrm{RMS}_{\text {aerobiose }}\right) / 100\right]$.

Letras distintas acima das barras diferiram estatisticamente $(P<0,05)$.

Erro padrão da média $=1,14$.

O período em que ocorreu a maior perda foi durante a fermentação, principalmente em razão da elevada concentração de umidade da planta (Figura 2), que acarreta a lixiviação de nutrientes na forma de efluente e o desenvolvimento de microrganismos que provocam fermentações indesejáveis.

Como relatado anteriormente, quando as silagens de capim-marandu são expostas ao ambiente, se tornam pouco propensas à deterioração aeróbia. Os aditivos estudados não foram eficientes em reduzir as perdas, tanto durante a fermentação ou quando estiveram presentes ao $\mathrm{O}_{2}$.

As rações não diferiram estatisticamente quanto ao consumo de MS (kg/dia e \% PC), MO (kg/dia) e FDN (\% PC). As quantidades médias de ração ingerida em $\mathrm{kg}$ MS e kg $\mathrm{MO} /$ dia foram de 5,7 e 4,6 kg, respectivamente, o que correspondeu a 1,6\% do peso corporal (kg MS) (Tabela 7). Valores semelhantes foram encontrados por Silva et al. (2005), que avaliaram a ingestão de novilhos (peso corporal médio = $364 \mathrm{~kg}$ ) alimentados com rações à base de silagem de capim-marandu e com diferentes proporções de concentrado e encontraram consumo de 5,3 e 4,9 ( $\mathrm{kg} \mathrm{MS} \mathrm{e} \mathrm{kg} \mathrm{MO/dia,}$ respectivamente) na ração com $20 \%$ de concentrado e $80 \%$ de volumoso.

Paziani (2004) avaliou a ingestão de rações com alta proporção de silagem de capim-tanzânia (86,6\% base MS) em novilhos Nelore com peso corporal médio de $415 \mathrm{~kg}$ e encontrou consumo médio de 4,5 kg MS/dia (1,1\% PC). Segundo esse autor, a ingestão ficou abaixo da média descrita pelo NRC (1996), de 8,6 kg/animal/dia, o que acarretou perda de peso dos animais durante o período experimental. Neste 
estudo, as previsões feitas com base nas equações do NRC (1996) também superestimaram o consumo, porém, houve ganhos marginais (em torno de $120 \mathrm{~g} / \mathrm{animal} / \mathrm{dia}$ ).

Assim como na variável consumo, a digestibilidade da ração não diferiu $(\mathrm{P}>0,05)$ entre as silagens. As digestibilidades médias da MS e da MO foram de 51,6 e 54,5\%, respectivamente, valores comumente observados em rações com alta proporção de silagem de gramínea tropical.

Nem mesmo a presença de enzimas fibrolíticas nas silagens LPPA e LPPA + LB provocou alterações no consumo e na digestibilidade das rações. Loures et al. (2005) avaliaram o valor nutritivo de rações contendo silagens de capim-tanzânia tratadas com enzimas e concluíram que a aplicação da preparação enzimática na ração minutos antes do fornecimento proporcionou os melhores resultados de digestibilidade da fração fibrosa. Esses autores encontraram valores médios de 53,2 e $56,0 \%$ para a digestibilidade aparente da MS e MO, respectivamente, embora a ração utilizada tivesse maior participação de concentrado (50:50).

As perdas do total removido diariamente dos silos foram superiores nas silagens com presença de inóculo, principalmente naquela tratada com LPPA+LB. A partir do sétimo dia de alimentação dos animais, os silos LPPA e LPPA+LB apresentaram sinais claros de aquecimento da massa, presença de fungos e elevação do $\mathrm{pH}$. O avanço diário na massa (média de $18 \mathrm{~cm}$ ) não foi suficiente para inibir que o fenômeno de deterioração aeróbia ocorresse, o que possivelmente determinou redução do consumo e digestibilidade destas silagens.

Tabela 7 - Perdas por deterioração aeróbia, consumo e digestibiliddade das rações contendo silagens de capim-marandu tratado com bactérias homo e heterofermen-tativas, isoladas ou associadas (experimento 2)

\begin{tabular}{|c|c|c|c|c|}
\hline \multirow[t]{2}{*}{ Variável } & \multicolumn{3}{|c|}{ Tratamento $^{1}$} & \multirow[t]{2}{*}{$\mathrm{EPM}^{2}$} \\
\hline & Controle & LPPA & $\mathrm{LPPA}+\mathrm{LB}$ & \\
\hline Perdas $(\%)^{3}$ & 19,9 & 25,8 & 34,0 & - \\
\hline \multicolumn{5}{|l|}{ Consumo } \\
\hline kg MS/dia & 5,8 & 5,6 & 5,7 & 0,22 \\
\hline kg MO/dia & 4,7 & 4,4 & 4,5 & 0,22 \\
\hline kg MS (\% PC) & 1,6 & 1,6 & 1,6 & 0,04 \\
\hline kg FDN (\% PC) & 1,2 & 1,2 & 1,2 & 0,03 \\
\hline \multicolumn{5}{|c|}{ Digestibilidade aparente } \\
\hline MS (\%) & 53,3 & 50,4 & 51,0 & 0,78 \\
\hline MO (\%) & 56,0 & 54,0 & 53,6 & 0,86 \\
\hline
\end{tabular}

${ }^{1} \mathrm{LPPA}=$ L. plantarum, $P$. acidilactici + celulase e hemicelulase, $\mathrm{LPPA}+\mathrm{LB}=$ LPPA + L. buchneri.

2 EPM = erro-padrão da média.

3 Perdas do total removido diariamente dos silos - média da avaliação de 44 dias.
A alta proporção de partículas com tamanho acima de $20 \mathrm{~mm}$, a alta concentração de fibra e de MS da planta dificultaram a compactação da massa, resultando em densidade de $495 \mathrm{~kg} / \mathrm{m}^{3}$. Além da porosidade da massa, a concentração de nutrientes é relevante na estabilidade aeróbia e as silagens LPPA e LPPA+LB podem ter se tornado mais instáveis com a inoculação com bactérias homofermentantes, pois o lactato pode ser assimilado pelas leveduras oxidativas, como foi observado no trabalho de Weinberg et al. (1993), embora alguns autores, como Meeske \& Basson (1998), não tenham encontrado efeito negativo em silagens inoculadas com L. pantarum, L. bulgaricus e L. acidophilus expostas ao ar.

Paziani et al. (2005) avaliaram silagens de capim-tanzânia com concentração de umidade original (24,5\% MS), inoculadas ou não, e silagens de capim emurchecido (27,7\% de MS) e verificaram que as perdas por deterioração foram maiores na silagem com capim emurchecido $(29,1 \%)$ e naquela com aditivo $(22,5 \%)$ e que a silagem com umidade original e sem inoculante apresentou perda de $15,5 \%$.

\section{Conclusões}

O uso de benzoato de sódio e de inoculantes contendo Lactobacillus plantarum e Propionibacterium ou Lactobacillus buchneri isoladamente não reduz as perdas de matéria seca durante a fermentação nem favorece a estabilidade aeróbia de silagens de capim-marandu com alta concentração de umidade. A inoculação com Lactobacillus plantarum, Pediococcus acidilactici + celulase e hemicelulase e a associação destas bactérias e enzimas com Lactobacillus buchneri não altera o consumo e a digestibilidade aparente de rações contendo alta proporção de silagem de capim-marandu.

\section{Agradecimento}

À Fundação de Amparo à Pesquisa do Estado de São Paulo (FAPESP). A Rafael Rodrigues Monteiro, aluno do curso de Zootecnia da FCAV/UNESP, pela colaboração durante os experimentos.

\section{Literatura Citada}

ANDRADE, S.J.T.; MELOTTI, L. Inoculantes bacterianos na ensilagem do capim-elefante (Pennisetum purpurem, Schum). Brazilian Journal of Veterinary Research and Animal Science, v.40, p.219-223, 2003.

BERNARDES, T.F.; REIS, R.A.; SCHOCKEN-ITURRINO, R.P Dinâmica microbiológica e alterações químicas das silagens de capim-Marandu (Brachiaria brizantha cv. Marandu) após a abertura dos silos. REUNIÃO ANUAL DA SOCIEDADE 
BRASILEIRA DE ZOOTECNIA, 40., 2003, Santa Maria. Anais... Santa Maria: Sociedade Brasileira de Zootecnia, 2003. (CD-ROM).

BERNARDES, T.F.; REIS, R.A.; MOREIRA, A.L. Fermentative and microbiological profile of marandu grass ensiled with citrus pulp pellets. Scientia Agricola, v.62, p.214-220, 2005.

BERNARDES, T.F.; REIS; R.A.; SIQUEIRA, G.R. et al. Estabilidade aeróbia da ração total e de silagens de capim-marandu tratadas com aditivos químicos e bacterianos. Revista Brasileira de Zootecnia, v.36, p.754-762, 2007.

CAMARGO, M.S.; NUSSIO, L.G.; FLEURY, D. et al. Estabilidade aeróbia de silagem de Brachiaria brizantha cv. Marandu submetida a diferentes técnicas de desidratação. In: REUNIÃO ANUAL DA SOCIEDADE BRASILEIRA DE ZOOTECNIA, 41. 2004, Campo Grande. Anais... Campo Grande: Sociedade Brasileira de Zootecnia, 2004. (CD-ROM).

COAN, R.M.; VIEIRA, P.F.; SILVEIRA, R.N. Inoculante enzimáticobacteriano, composição química e parâmetros fermentativos das silagens dos Tanzânia e mombaça. Revista Brasileira de Zootecnia, v.34, p.416-424, 2005.

DRIEHUIS, F.; OUDE ELFERINK, W.H.; Van WIKSELAAR, P.G. Fermentation characteristics and aerobic stability of grass silage inoculant with Lactobacillus buchneri, with or without homofermentative lactic acid bacteria. Grass and Forage Science, v.56, p.330-343, 2001

FLORES-GALARZA, R.A.; GLATZ, B.A.; BERN, C.J. et al. Preservation of high-moisture corn by microbial fermentation. Journal of Food Protection, v.48, p.407-411, 1985.

KUNG JR., L.; GRIEVE, D.B.; THOMAS, J.W. Added ammonia or microbial inoculant for fermentation and nitrogenous compounds of alfalfa ensiled at various percents of dry matter. Journal of Dairy Science, v.67, p.299-306, 1984.

KUNG JR., L.; STOKES, M.R.; LIN, C.J. Silage additives. In: BUXTON, D.R.; MUCK, R.E.; HARRISON, J.H. (Eds.) Silage science and technology. 1.ed. Madison: American Society of Agronomy, 2003a. p.305-360.

KUNG JR., L.; TAYLOR, C.C.; LYNCH, M.P. et al. The effect of treating alfalfa with Lactobacillus buchneri 40788 on silage fermentation, aerobic stability, and nutritive value for lactating dairy cows. Journal of Dairy Science, v.86, p.336-343, 2003b.

LOURES, D.R.S.; GARCIA, R.; PEREIRA, O.G. et al. Características do efluente e composição químico-bromatológica da silagem de capim-elefante sob diferentes níveis de compactação. Revista Brasileira de Zootecnia, v.32, p.1851-1858, 2003.

LOURES, D.R.S.; NUSSIO, L.G.; PAZIANI, S.F. Efeito de enzimas fibrolíticas e do teor de matéria seca em silagens de capimtanzânia sobre os parâmetros ruminais, o comportamento ingestivo e a digestão de nutrientes, em bovinos. Revista Brasileira de Zootecnia, v.34, p.736-745, 2005.

MARI, L.J. Intervalo entre cortes em capim-Marandu (Brachiaria brizantha (Hochst. Ex A. Rich.) Stapf cv. Marandu): produção, valor nutritivo e perdas associadas à fermentação da silagem. Piracicaba: Escola Superior de Agricultura Luiz de Queiroz, 2003. 138p. Dissertação (Mestrado em Ciência Animal e Pastagens) - Escola Superior de Agricultura Luiz de Queiroz, Universidade de São Paulo, 2003.
MEESKE, R.; BASSON, H.M. The effect of a lactic acid bacterial inoculant on maize silage. Animal Feed Science and Technology, v.70, p.239-247, 1998.

McDONALD, P.; HENDERSON, A.R.; HERON, S.J.E. Biochemistry of silage. 2.ed. Marlow: Chalcombe Publication, 1991. 340p.

MORAN, J.P.; WEINBERG, Z.G.; AHSBELL, G. et al. A comparison of two methods for the evaluation of the aerobic stability of whole crop wheat silage. In: THE INTERNATIONAL SILAGE CONFERENCE, 11., 1996, Aberystwyth. Proceedings... Aberystwyth, 1996. p.162-163.

MUCK, R.E. Effects of corn silage inoculants on aerobic stability. Transactions of the ASABE, v.47, p.1011-1016, 2004.

NATIONAL RESEARCH COUNCIL - NRC. Nutrient requirements of beef cattle. 7.ed. Washington, D.C.: National Academy of Science. 1996. 242p.

NISHINO, N.; YOSHIDA, M.; SHIOTA, H. et al. Accumulation of 1,2 propanediol and enhancement of aerobic stability in whole crop maize silage inoculated with Lactobacillus buchneri. Journal of Applied Microbiology, v.94, p.800-807, 2003.

ÖSTLING, C.; LINDGREN, S. Influences of enterobacteria on the fermentation and aerobic stability of grass silages. Grass and Forage Science, v.50, p.41-47, 1995.

PAHLOW, G.; MUCK, R.E.; DRIEHUIS, F. et al. Microbiology of ensiling. In: BUXTON, D.R.; MUCK, R.E.; HARRISON, J.H. (Eds). Silage science and technology. 1.ed. Madison: American Society of Agronomy, 2003. p.31-94.

PAZIANI, S.F. Controle de perdas na ensilagem, desempenho e digestão de nutrientes em bovinos de corte alimentados com rações contendo silagens de capim-Tanzânia. Piracicaba: Escola Superior de Agricultura Luiz de Queiroz, Universidade de São Paulo, 2004. 208p. Tese (Doutorado em Ciência Animal e Pastagem) - Escola Superior de Agricultura Luiz de Queiroz, 2004.

PAZIANI, S.F.; NUSSIO, L.G.; LOURES, D.R.S. et al. Moisture control, inoculant and particle size in tropical grass silages. In: THE INTERNATIONAL SILAGE CONFERENCE, 14., 2005, Belfast. Proceedings... Belfast: 2005a. p.258.

ROBERTSON, J.B.; Van SOEST, P.J. The detergent system of analysis and its application to human foods. In: JAMES, W.P.T.; THEANDER, O. (Eds). The analysis of dietary fiber in food. New York: Marcel Dekker, 1981. p.123-158.

STATISTICAL ANALYSES SYSTEM - SAS. SAS/STAT. User's Guide. Version 8. Cary: 1999. (CD-ROM).

SILVA, D.J.; QUEIROZ, A.C. Análise de alimentos: métodos químicos e biológicos. 3.ed. Viçosa, MG: Edotira UFV, 2002. 235p.

SILVA, B.C.; PEREIRA, O.G.; PEREIRA, D.H. Consumo e digestibilidade aparente total dos nutrientes e ganho de peso de bovinos de corte alimentados com silagem de Brachiaria brizantha e concentrado em diferentes proporções. Revista Brasileira de Zootecnia, v.34, p.1060-1069, 2005.

WEINBERG, Z.G.; ASHBELL, G.; HEN, Y. et al. The effect of applying lactic acid bacteria at ensiling on the aerobic stability of silages. Journal of Applied Bacteriology, v.75, p.512-518, 1993.

WINTERS, A.L.; WHITTAKER, P.A.; WILSON, R.K. Microscopic and chemical changes during the first 22 days in Italian ryegrass and cocksfoot silages made in laboratory silos. Grass and Forage Science, v.42, p.191-196, 1987. 